\title{
Enzyme-assisted extraction of phenolics from winemaking by-products: Antioxidant potential and inhibition of alpha-glucosidase and lipase activities
}

\author{
Adriano Costa de Camargo ${ }^{\mathrm{a}, \mathrm{b}}$, Marisa Aparecida Bismara Regitano-d'Arce ${ }^{\mathrm{b}}$, Aline Camarão Telles Biasoto ${ }^{\mathrm{c}}$, \\ Fereidoon Shahidi ${ }^{\text {a,* }}$ \\ a Department of Biochemistry, Memorial University of Newfoundland, St. John's, NL A1B 3X9, Canada

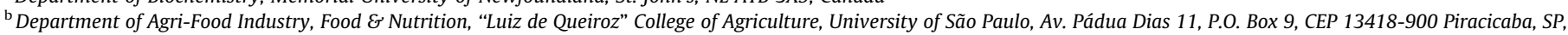 \\ Brazil \\ ${ }^{\mathrm{c}}$ Embrapa Semiárido, Rodovia BR 428, km 152, P.O. Box 23, CEP 56302-970 Petrolina, PE, Brazil
}

\section{A R T I C L E I N F O}

Article history:

Received 10 February 2016

Received in revised form 31 March 2016

Accepted 9 May 2016

Available online 10 May 2016

\section{Keywords:}

HPLC-DAD-ESI-MS ${ }^{n}$

Phenolic acids

Flavonoids

Proanthocyanidin

Diabetes

Obesity

\begin{abstract}
A B S T R A C T
Phenolics in food and agricultural processing by-products exist in the soluble and insoluble-bound forms. The ability of selected enzymes in improving the extraction of insoluble-bound phenolics from the starting material (experiment I) or the residues containing insoluble-bound phenolics (experiment II) were evaluated. Pronase and Viscozyme improved the extraction of insoluble-bound phenolics as evaluated by total phenolic content, antioxidant potential as determined by ABTS and DPPH assays, and hydroxyl radical scavenging capacity, reducing power as well as evaluation of inhibition of alpha-glucosidase and lipase activities. Viscozyme released higher amounts of gallic acid, catechin, and prodelphinidin dimer A compared to Pronase treatment. Furthermore, $p$-coumaric and caffeic acids, as well as procyanidin dimer B, were extracted with Viscozyme but not with Pronase treatment. Solubility plays an important role in the bioavailability of phenolic compounds, hence this study may assist in better exploitation of phenolics from winemaking by-products as functional food ingredients and/or supplements.
\end{abstract}

(C) 2016 Published by Elsevier Ltd.

\section{Introduction}

Grapes and their derived beverages are important sources of food phenolics (da Silva et al., 2016; Tao et al., 2016). However, winemaking generates a large amount of by-products (e.g. skins and seeds). These by-products serve as rich sources of phenolics belonging to several classes of compounds such as phenolic acids, flavonoids, including anthocyanins, as well as proanthocyanidins (Cheng, Bekhit, McConnell, Mros, \& Zhao, 2012; de Camargo, Regitano-d'Arce, Biasoto, \& Shahidi, 2014).

Phenolic and/or polyphenolic compounds have attracted much attention due to their wide range of potential health benefits, as substantiated by both in vitro and in vivo studies (de Camargo et al., 2014; Vicente, Ishimoto, \& Torres, 2014). The role of food phenolics in preventing degenerative, vascular and heart disease and as anti-inflammatory and antimicrobial agents have also been reported (Alasalvar \& Bolling, 2015; Shahidi \& Ambigaipalan, 2015). Additionally, phenolic compounds may play an important

\footnotetext{
* Corresponding author.

E-mail address: fshahidi@mun.ca (F. Shahidi).
}

role in amiliorating certain types of cancer, including colorectal cancer (Shahidi \& Ambigaipalan, 2015). The chemical structures of these molecules are as important as their detection and concentration, which may reflect in a different correlation between a particular molecule and its activity.

Phenolic compounds are present in the soluble (free and esterified) and insoluble-bound forms, the proportion of each one depends not only on the starting material but also on their cultivar and an eventual processing to which they are subjected. For example, the esterified phenolics from lentils were generally in higher amount, but some cultivars also showed higher content in the fraction containing insoluble-bound phenolics (Alshikh, de Camargo, \& Shahidi, 2015), whereas berry seed meals had higher content of insoluble-bound phenolics (Ayoub, de Camargo, \& Shahidi, 2016). Peanut skin submitted to gamma-irradiation had increased free and insoluble-bound phenolic contents upon processing (de Camargo, Regitano-d'Arce, Gallo, \& Shahidi, 2015). As antioxidants, phenolic compounds may counteract oxidative reactions in food subjected to treatments such as gamma irradiation and pasteurization as well as during long-term storage, which may affect its shelflife and sensory characteristics (da Silva et al., 2014; de Camargo at 
al., 2012a). Furthermore, biologically relevant molecules such as lipids, proteins, lipoproteins and DNA may also be protected from oxidatively reactive compounds.

In a previous study at this department (de Camargo et al., 2014), it has been demonstrated that, regardless of the process (juice or winemaking), insoluble-bound phenolics were major fractions in grape processing by-products. The same study also provided evidence about the dominant benefits of insoluble-bound phenolics of grape by-products in inhibiting copper-induced human LDLcholesterol oxidation and peroxyl radical-induced DNA strand breakage. These results demonstrated the potential of the insoluble-bound phenolics from winemaking by-products as their major source of bioactive compounds.

Enzyme-assisted extraction has been regarded as an alternative method for improved extraction of food phenolics (Montella et al., 2013; Papillo, Vitaglione, Graziani, Gokmen, \& Fogliano, 2014), especially the insoluble-bound phenolics, which are linked to carbohydrates and proteins of cell wall matrices. However, to the best of the authors' knowledge, there is no literature providing the effect of enzyme-assisted extraction on the ratio of soluble to insoluble-bound phenolics from winemaking by-products although this has been reported for germinating lentils by Yeo and Shahidi (2015). Thus, in the present study, winemaking byproducts (cv. Tempranillo) were treated with Pronase and Viscozyme to improve the solubility of phenolics present in the sample. The effects were studied based on the change in the distribution pattern of soluble/insoluble-bound phenolics as well as their chemical profile, antioxidant properties (antiradical activity) and reducing power. The resultant products were also evaluated for their effect in deactivating alpha-glucosidase and lipase, which have a key role in the prevention and management of diabetes and obesity, respectively.

\section{Material and methods}

Winemaking by-products (cv. Tempranillo) were kindly provided by Santa Maria Winery (Lagoa Grande, Pernambuco State, Brazil). Hexane, acetone, diethyl ether, ethyl acetate, methanol, acetonitrile, formic acid, hydrochloric acid, sodium hydroxide, potassium persulfate, sodium chloride, trichloroacetic acid, sodium carbonate, dimethyl sulphoxide and Tris base were purchased from Fisher Scientific Ltd. (Ottawa, ON, Canada). Pronase, Viscozyme, alpha-glucosidase from Saccharomyces cerevisiae, and type II crude porcine pancreatic lipase, catalogue numbers P5147, V2010, G5003, and L3126, respectively, as well as Folin Ciocalteau's phenol reagent, DPPH, ABTS, mono- and dibasic potassium phosphates, hydrogen peroxide, DMPO (5,5-dimethyl-1-pyrroline- $N$-oxide), ferrous sulphate, potassium ferricyanide, ferric chloride, Trolox, $p$-nitrophenyl $\beta$-D-glucopyranoside, $p$-nitrophenyl octanoate, caffeic, gallic, and $p$-coumaric acids, catechin and epicatechin were purchased from Sigma-Aldrich Canada Ltd. (Oakville, ON, Canada).

\subsection{Effect of enzyme treatment on the starting material (Experiment I)}

The first experiment was designed to study the effect of pretreatment of selected enzymes on the soluble/insoluble-bound phenolic ratio and in vitro bioactivity. The sample (50 g) was freeze dried at $-48^{\circ} \mathrm{C}$ and $30 \times 10^{-3}$ mbar (Freezone 6, model 77530 , Labconco Co., Kansas City, MO), ground with a coffee bean grinder (Model CBG5 series, Black \& Decker, Canada Inc., Brockville, ON, Canada) and the powder was passed through a mesh 16 (sieve opening $1 \mathrm{~mm}$, Tyler test sieve, Mentor, $\mathrm{OH}$ ) sieve. The powder so obtained was defatted three times with hexane (solid/solvent, 1:5, w/v) using a Warring blender (Model 33BL73, Warring Products Division Dynamics Co. of America, New Hartford, CT). Defatted samples were recovered by vacuum filtration and stored at $-20^{\circ} \mathrm{C}$ (de Camargo et al., 2014). Defatted samples $(10 \mathrm{~g})$ were suspended in $100 \mathrm{~mL}$ of Viscozyme solution ( $2 \%$ in $0.1 \mathrm{M}$ phosphate buffer, $\mathrm{pH}$ 4) and stirred for $12 \mathrm{~h}$ at $37^{\circ} \mathrm{C}$ in a gyratory water bath shaker (Model. G76, New Brunswick Scientific Co. Inc., New Brunswick, $\mathrm{NJ}$ ) or $100 \mathrm{~mL}$ of Pronase solution $(1 \mathrm{mg} / \mathrm{mL}$ in $0.1 \mathrm{M}$ phosphate buffer, $\mathrm{pH} 8$ ) and stirred for $1 \mathrm{~h}$. Controls containing each respective buffer (devoid of enzyme) were prepared at the same time and under the same conditions. Treated samples and respective controls were freeze dried to obtain a dry powder and further used for extraction of soluble and insoluble-bound phenolics (within one week). The extraction of soluble phenolics was carried out with $70 \%(\mathrm{v} / \mathrm{v})$ acetone $(2.5 \%, \mathrm{w} / \mathrm{v})$ in a gyratory water bath shaker at $30^{\circ} \mathrm{C}$ for $20 \mathrm{~min}$. After centrifugation at $4000 \mathrm{~g}$ (IEC Centra MP4, International Equipment Co., Needham Heights, MA), the upper layer was collected and the extraction was repeated twice. The combined supernatants were evaporated under vacuum at $40^{\circ} \mathrm{CC}$ (Buchi, Flawil, Switzerland) to remove the organic solvent. The extract so obtained (soluble phenolics) was stored at $-20^{\circ} \mathrm{C}$ until used for further analysis within three months. To the dry residue remaining after the extraction of soluble phenolics, $4 \mathrm{M} \mathrm{NaOH}$ was added, and hydrolyzed, while stirring under nitrogen for $4 \mathrm{~h}$ at room temperature $\left(23-25^{\circ} \mathrm{C}\right)$. The resulting slurry was acidified to $\mathrm{pH} 2$ with $6 \mathrm{M} \mathrm{HCl}$. Phenolics released from their insolublebound form were then extracted with diethyl ether and ethyl acetate $(1: 1, v / v)$, and reconstituted in HPLC-grade methanol (de Camargo et al., 2014).

\subsection{Effect of enzyme treatment on the residue remaining after extraction of soluble phenolics (Experiment II)}

The second experiment was carried out to evaluate the effect of enzyme treatment on the yield and identity of phenolics remaining after extraction of its soluble counterpart. The effect of enzyme treatment on the in vitro bioactivity was also evaluated. In short, the extraction of soluble phenolics was carried out with $70 \%(\mathrm{v})$ v) acetone as described above, and only the dry residue remaining after this extraction was treated with Viscozyme or Pronase, using the aforementioned conditions. After enzyme treatment the resulting slurry was acidified to $\mathrm{pH} 2$ with $6 \mathrm{M} \mathrm{HCl}$. Phenolics released from their insoluble-bound form upon enzyme treatment were then extracted with diethyl ether and ethyl acetate $(1: 1, v / v)$, and reconstituted in HPLC-grade methanol. To compare results, an alkali hydrolysis was carried out as described above. Thus, three different extracts were obtained in this experiment (phenolics released from their insoluble-bound form upon Viscozyme, Pronase, and $\mathrm{NaOH}$ treatment).

\subsection{Total phenolic content (TPC)}

The TPC (Swain \& Hillis, 1959) was evaluated using the same procedure and equipment as described elsewhere (de Camargo, Vidal, Canniatti-Brazaca, \& Shahidi, 2014). The results were expressed as milligram gallic acid equivalents (GAE) per gram of defatted samples.

\subsection{HPLC-DAD-ESI-MS ${ }^{n}$ analysis}

HPLC-DAD-ESI-MS ${ }^{n}$ analyses were conducted to investigate the effect of Viscozyme and Pronase treatments on the residue remaining after extraction of soluble phenolics. This allowed for the positive, or tentative, identification and quantification of major phenolics as affected by each treatment. The extract obtained using alkali extraction was also evaluated. This approach was chosen to examine the effects of enzyme treatment on the fraction containing insoluble-bound phenolics and individual components present, 
lending further support to the findings from the first experiment. The analyses were performed using an Agilent 1100 system equipped with a G1311A quaternary pump, a G1379A degasser and a G1329A ALS automatic sampler, a G1130B ALS Therm, a G1316 Colcom column compartment, A G1315B diode array detector (DAD) and a system controller linked to Chem Station Data handling system (Agilent). Separations were conducted with a SUPERLCOSILTM LC-18 column $(4.6 \times 250 \mathrm{~mm} \times 5 \mu \mathrm{m}$, Merck, Darmstad, Germany). HPLC-ESI-MS ${ }^{\mathrm{n}}$ analysis was carried out using an Agilent 1100 series capillary liquid chromatography/mass selective detector (LC/MSD) ion trap system in electrospray ionization (ESI) in the negative mode. The data were acquired and analyzed with an Agilent LC/MSD software. Details of the method have been published elsewhere (de Camargo et al., 2014).

\subsection{ABTS radical cation scavenging activity}

The ABTS assay (Re et al., 1999) was conducted using the method and equipment, as described elsewhere (de Camargo and Vidal et al., 2014). The results were expressed as $\mu \mathrm{mol}$ of Trolox equivalents/g dry weight of defatted samples.

\subsection{DPPH radical scavenging activity}

The ability of phenolic extracts in scavenging DPPH radical was evaluated using a Bruker E-Scan electron paramagnetic resonance (EPR) spectrophotometer (Bruker E-Scan, Bruker Biospin Co., Billerica, MA). Experimental procedure and equipment parameters were the same as those described by de Camargo and Vidal et al. (2014). The results were expressed as $\mu \mathrm{mol}$ of Trolox equivalents/g dry weight of defatted samples.

\subsection{Hydroxyl radical scavenging activity}

Phenolic extracts were tested for their scavenging activity against hydroxyl radicals. The extracts were removed from their original solvent (methanol) under a stream of nitrogen and diluted in $75 \mathrm{mM}$ phosphate buffer, pH 7.2 (Ambigaipalan, Al-Khalifa, \& Shahidi, 2015). A Bruker E-Scan electron paramagnetic resonance (EPR) spectrophotometer (Bruker E-Scan, Bruker Biospin Co., Billerica, MA) was used. The method details have already been published (de Camargo and Vidal et al., 2014) and the results were expressed as $\mu \mathrm{mol}$ of catechin equivalents/g dry weight of defatted samples.

\subsection{Reducing power}

The reducing power assay (Oyaizu, 1986) was carried out as described elsewhere (de Camargo and Vidal et al., 2014). Trolox was used to prepare the standard curve and the results were expressed as $\mu \mathrm{mol}$ of Trolox equivalents/g dry weight of defatted samples.

\subsection{Inhibition of alpha-glucosidase activity}

The ability of phenolic extracts in inhibiting the activity of alpha-glucosidase was evaluated according to the method of Eom et al. (2012), using $p$-nitrophenyl $\beta$-D-glucopyranoside as a substrate. In this assay, alpha-glucosidase hydrolyzes $p$-nitrophenyl $\beta$-D-glucopyranoside to generate glucose and $p$-nitrophenol. The latter one is used for quantification purposes (chromogenic substance). Alpha-glucosidase solution (10 units/mL) was prepared in $0.1 \mathrm{M}$ potassium phosphate buffer ( $\mathrm{pH}$ 6.8). The enzyme solution $(5 \mu \mathrm{L})$ was mixed with $10 \mu \mathrm{L}$ of phenolic extracts $(50 \mathrm{mg} / \mathrm{mL})$, and an aliquot of $0.1 \mathrm{M}$ potassium phosphate buffer was added $(620 \mu \mathrm{L})$. The mixture was incubated at $37^{\circ} \mathrm{C}$ for $20 \mathrm{~min}$ and $10 \mathrm{mM} p$-nitrophenyl $\beta$-D-glucopyranoside $(10 \mu \mathrm{L})$ was added to initiate the reaction, which was followed by incubation at $37^{\circ} \mathrm{C}$ for $20 \mathrm{~min}$. The reaction was terminated by the addition of $1 \mathrm{M}$ sodium carbonate solution $(650 \mu \mathrm{L})$. The absorbance was read at $410 \mathrm{~nm}$ using an Agilent diode array spectrophotometer (Agilent 8453 , Palo Alto, CA). Blanks devoid of enzyme (added by phosphate buffer) were prepared for background corrections. The control consisted of all solutions but the phenolic extract. The percentage of inhibition activity was calculated using the following equation:

$$
\begin{aligned}
& \text { Alpha-glucosidase inhibition }(\%) \\
& \quad=\left[\left(\mathrm{Abs}_{\text {control }}-\mathrm{Abs}_{\text {sample }}\right) /\left(\mathrm{Abs}_{\text {control }}\right)\right] \times 100
\end{aligned}
$$

\subsection{Inhibition of lipase activity}

The inhibition of activity of phenolic extracts towards lipase was evaluated as described by Marrelli et al. (2012), using pnitrophenyl octanoate (NPC) as a substrate which, in the presence of lipase, liberates $p$-nitrophenol and octanoic acid. As mentioned before, the former chromogenic substance is used for quantification purposes. Type II crude porcine pancreatic lipase was used at a concentration of $5 \mathrm{mg} / \mathrm{mL}$. The substract (NPC) was prepared in dimethyl sulphoxide to achieve a concentration of $5 \mathrm{mM}$. Phenolic extracts $(100 \mu \mathrm{L})$ were mixed with $4 \mathrm{~mL}$ of Tris- $\mathrm{HCl}$ buffer $(\mathrm{pH}$ $8.5)$ and enzyme solution $(100 \mu \mathrm{L})$. After incubation at $37^{\circ} \mathrm{C}$ for $25 \mathrm{~min}$, NPC $(100 \mu \mathrm{L})$ was added and incubated again at $37^{\circ} \mathrm{C}$ for $25 \mathrm{~min}$. The absorbance was read at $412 \mathrm{~nm}$ using an Agilent diode array spectrophotometer (Agilent 8453). Blanks, devoid of enzyme (added by Tris- $\mathrm{HCl}$ buffer), were prepared for background corrections. The control consisted of all solutions but the phenolic extract. The percentage of inhibition of activity was calculated using the following equation:

Lipase inhibition $(\%)=\left[\left(\mathrm{Abs}_{\text {control }}-\mathrm{Abs}_{\text {sample }}\right) /\left(\mathrm{Abs}_{\text {control }}\right)\right] \times 100$

\subsection{Statistical analysis}

Unless otherwise stated, the statistical analysis was randomized with three replications, and the results were analyzed using ANOVA and Tukey's test $(p<0.05)$ and SPSS statistics 21 for Windows (SPSS Inc., Chicago, IL). The correlation analyses $(p<0.05)$ were carried out using the same software.

\section{Results and discussion}

\subsection{Effect of enzyme treatment on the starting material (Experiment I)}

\subsubsection{Total phenolic content (TPC)}

The TPC was found to positively correlate with the inhibition of copper-induced human LDL-cholesterol oxidation and by both hydroxyl and peroxyl radical-induced DNA strand breakage (Ayoub et al., 2016; de Camargo et al., 2014). Thus, TPC may reflect the ability of food phenolics to prevent atherosclerosis, associated cardiovascular diseases and certain types of cancer. The TPC of samples (starting material) subjected to Pronase (Table 1) and Viscozyme (Table 2) treatment demonstrated that both enzymes affected the content of soluble and insoluble-bound phenolics, which was noted by an increase in the ratio of soluble to insoluble-bound phenolics. Soluble phenolics can be readily absorbed, whereas insoluble-bound phenolics remain available for microbial fermentation in the lower gut (Chandrasekara \& Shahidi, 2012). Thus, the increase of soluble phenolics may have a practical impact on the role of phenolics in the human body. 
Table 1

Effect of pre-treatment with Pronase on the total phenolic content, antioxidant activity, and reducing power of soluble (S) and insoluble-bound (IB) phenolics of winemaking by-products.

\begin{tabular}{|c|c|c|c|}
\hline & Soluble (S) & Insoluble-bound (IB) & Ratio (S/IB) \\
\hline \multicolumn{4}{|c|}{ Total phenolic content ( $m g$ GAE/g DW) } \\
\hline Control $^{*}$ & $265.6 \pm 8.75 \mathrm{Ba}$ & $257.9 \pm 3.25 \mathrm{Aa}$ & $0.88 \pm 0.08 B$ \\
\hline Pronase & $301.9 \pm 21.4 \mathrm{Aa}$ & $204.1 \pm 0.27 \mathrm{Bb}$ & $1.26 \pm 0.02 \mathrm{~A}$ \\
\hline \multicolumn{4}{|c|}{ ABTS radical cation scavenging activity ( $\mu \mathrm{mol} T E / g D W$ ) } \\
\hline Control & $512.2 \pm 17.2 \mathrm{Bb}$ & $784.9 \pm 8.42 \mathrm{Aa}$ & $0.65 \pm 0.03 B$ \\
\hline Pronase & $699.9 \pm 8.43 \mathrm{Aa}$ & $621.4 \pm 24.9 \mathrm{Bb}$ & $1.13 \pm 0.06 \mathrm{~A}$ \\
\hline \multicolumn{4}{|c|}{ DPPH radical scavenging activity ( $\mu \mathrm{mol} T E / g$ DW) } \\
\hline Control & $557.6 \pm 3.83 \mathrm{Bb}$ & $592.6 \pm 5.11 \mathrm{Aa}$ & $0.94 \pm 0.01 \mathrm{~B}$ \\
\hline Pronase & $728.4 \pm 30.5 \mathrm{Aa}$ & $558.2 \pm 2.32 \mathrm{Bb}$ & $1.30 \pm 0.05 \mathrm{~A}$ \\
\hline \multicolumn{4}{|c|}{ Hydroxyl radical cation scavenging activity ( $\mu$ mol CE/g DW) } \\
\hline Control & $275.7 \pm 0.91 \mathrm{Bb}$ & $323.7 \pm 3.82 \mathrm{Aa}$ & $0.85 \pm 0.01 \mathrm{~B}$ \\
\hline Pronase & $319.9 \pm 5.39 \mathrm{Aa}$ & $241.5 \pm 18.8 \mathrm{Bb}$ & $1.33 \pm 0.08 \mathrm{~A}$ \\
\hline \multicolumn{4}{|c|}{ Reducing power ( $\mu$ mol TE/g DW) } \\
\hline Control & $196.1 \pm 4.44 \mathrm{Bb}$ & $545.9 \pm 9.34 \mathrm{Aa}$ & $0.36 \pm 0.01 \mathrm{~B}$ \\
\hline Pronase & $250.4 \pm 1.97 \mathrm{Ab}$ & $464.0 \pm 5.50 \mathrm{Ba}$ & $0.54 \pm 0.00 \mathrm{~A}$ \\
\hline
\end{tabular}

* Control samples were treated with buffer $\mathrm{pH} 8$ under the same conditions as those treated with Pronase. Data represent mean values for each sample \pm standard deviation $(n=3)$. Means followed by different capital letters within a column part show difference between control and enzyme treated samples $(p<0.05)$. Means followed by different small letters within a row show difference between soluble and insoluble-bound fractions $(p<0.05)$. GAE, gallic acid equivalents; CE, catechin equivalents; TE, Trolox equivalents; and DW, dry weight of defatted sample.

\section{Table 2}

Effect of pre-treatment with Viscozyme on the total phenolic content, antioxidant activity, and reducing power of soluble (S) and insoluble-bound (IB) phenolics of winemaking by-products.

\begin{tabular}{|c|c|c|c|}
\hline & Soluble (S) & Insoluble-bound (IB) & Ratio (S/IB) \\
\hline \multicolumn{4}{|c|}{ Total phenolic content (mg GAE/g DW) } \\
\hline Control $^{*}$ & $322.7 \pm 6.79 \mathrm{Ba}$ & $256.0 \pm 5.69 \mathrm{Ab}$ & $0.87 \pm 0.02 B$ \\
\hline Viscozyme & $371.0 \pm 7.81 \mathrm{Aa}$ & $184.6 \pm 7.88 \mathrm{Bb}$ & $1.39 \pm 0.03 \mathrm{~A}$ \\
\hline \multicolumn{4}{|c|}{ ABTS radical cation scavenging activity ( $\mu \mathrm{mol} T E / g$ DW) } \\
\hline Control & $463.3 \pm 0.85 \mathrm{Bb}$ & $683.8 \pm 2.99 \mathrm{Aa}$ & $0.67 \pm 0.01 \mathrm{~B}$ \\
\hline Viscozyme & $695.0 \pm 10.5 \mathrm{Aa}$ & $509.6 \pm 2.75 \mathrm{Bb}$ & $1.34 \pm 0.01 \mathrm{~A}$ \\
\hline \multicolumn{4}{|c|}{$D P P H$ radical scavenging activity ( $\mu \mathrm{mol} T E / g D W)$} \\
\hline Control & $531.6 \pm 6.87 \mathrm{Bb}$ & $797.4 \pm 20.7 \mathrm{Aa}$ & $0.82 \pm 0.05 B$ \\
\hline Viscozyme & $652.2 \pm 30.0 \mathrm{Aa}$ & $442.7 \pm 15.1 \mathrm{Bb}$ & $1.80 \pm 0.02 \mathrm{~A}$ \\
\hline \multicolumn{4}{|c|}{ Hydroxyl radical cation scavenging activity ( $\mu \mathrm{mol} C E / g$ DW) } \\
\hline Control & $284.1 \pm 15.4 \mathrm{Ba}$ & $227.1 \pm 3.49 \mathrm{Ab}$ & $1.25 \pm 0.05 B$ \\
\hline Viscozyme & $414.4 \pm 8.30 \mathrm{Aa}$ & $163.4 \pm 1.22 \mathrm{Bb}$ & $2.54 \pm 0.03 \mathrm{~A}$ \\
\hline \multicolumn{4}{|c|}{ Reducing power ( $\mu$ mol TE/g DW) } \\
\hline Control & $189.6 \pm 1.71 \mathrm{Bb}$ & $292.2 \pm 35.4 \mathrm{Ab}$ & $0.32 \pm 0.02 B$ \\
\hline Viscozyme & $595.3 \pm 35.4 \mathrm{Aa}$ & $471.5 \pm 4.61 \mathrm{Ba}$ & $0.62 \pm 0.01 \mathrm{~A}$ \\
\hline
\end{tabular}

Control samples were treated with buffer $\mathrm{pH} 4$ under the same conditions as those treated with Viscozyme. Data represent mean values for each sample \pm standard deviation $(n=3)$. Means followed by different capital letters within a column part show difference between control and enzyme treated samples $(p<0.05)$. Means followed by different small letters within a row show difference between soluble and insoluble-bound fractions $(p<0.05)$. GAE, gallic acid equivalents; CE, catechin equivalents; TE, Trolox equivalents; and DW, dry weight of defatted sample.

\subsubsection{Antiradical activity and reducing power}

Pronase and Viscozyme may serve as alternatives for extracting phenolic antioxidants from different sources (Montella et al., 2013; Papillo et al., 2014). The presence, number and configuration of the hydroxyl groups may have an important effect in biochemical reactions such as those involving single electron transfer and hydrogen atom transfer, which are related to the ability of phenolic compounds in deactivating reactive oxygen species (ROS) and/or metal ions (Ayoub et al., 2016; de Camargo et al., 2014). Different assays might render different results, which stem from the mechanisms by which they are operate. Therefore, besides TPC, the antioxidant activity was evaluated using ABTS, DPPH assays, and antiradical activity against hydroxyl radicals in the present study. Furthermore, the reducing power was also evaluated.

The effect of Pronase and Viscozyme pre-treatment is shown in Tables 1 and 2, respectively. Phenolic extracts obtained from the samples treated with selected enzymes demonstrated activity using all methods but, most importantly, the results lend support to the change of the ratio noted between the fraction containing soluble and insoluble-bound phenolics, which increased upon enzyme treatment of the starting material. A representative demonstration of the effect is shown in Fig. 1, as evaluated by the ability of the phenolics extracted from the control (devoid of enzyme) and the starting material pre-treated with Pronase in scavenging hydroxyl radicals. The same trend was observed when the starting material was treated with Viscozyme. The higher the EPR signal, the lower the scavenging activity. Hydroxyl radicals are unstable and highly ROS, they can cause DNA damage, lipid and protein oxidation. Furthermore, these ROS are related to cell damage, cancer development, inflammation and heart disease.

The results obtained with DPPH, ABTS, and reducing power methods have been shown to correlate with the concentration of specific phenolics found in grapes such as catechin, quercetin, epicatechin gallate, kaempferol hexoside, and procyanidin dimer B (de Camargo et al., 2014). Gallic and caffeic acid as well as catechin, epicatechin gallate, and procyanidin trimer $\mathrm{C}$ were positively correlated with the scavenging activity towards hydrogen peroxide (de Camargo et al., 2014). Caffeic acid, quercetin and procyanidin dimer B correlated with ORAC assay results (Ayoub et al., 2016), which demonstrates the ability of phenolic extracts in scavenging peroxyl radicals. Therefore, the change in the antioxidant activity and reducing power found between soluble and insoluble-bound phenolics may be explained not only on the basis of TPC, but may also be related to specific phenolics extracted upon pretreatment with Pronase and Viscozyme.

\subsubsection{Inhibition of alpha-glucosidase and lipase activities}

Different medicines are available to manage diabetes and obesity; however, their use may result in a wide range of side effects. Furthermore, in some countries, like Brazil, medications such as anti-hyperglycaemics are provided by the government, which may become a national economic burden. Phenolic compounds have shown inhibitory activity towards alpha-glucosidase and lipase which are key enzymes regulating the absorption of glucose and triacylglycerol, respectively, in the small intestine (Zhang et al., 2015). Thus, the inhibition of both these enzymes was used as a biological model system in the present study.

The inhibition of phenolic extracts towards alpha-glucosidase and lipase activities is shown in Fig. 2A-D. The inhibition percentage of soluble phenolics against alpha-glucosidase activity increased from 75.6 $\pm 2.5-93.7 \pm 0.5$ in samples treated with Pronase and from $84.5 \pm 0.5-96.5 \pm 2.9$ in samples treated with Viscozyme. A concurrent decreasing trend was noted in the ability of insoluble-bound phenolics towards alpha-glucosidase. As mentioned before, alpha-glucosidase plays an important role in the absorption of glucose; therefore, the increase in the extraction of soluble-phenolics, which are readily absorbed in the small intestine, may have a positive impact on the prevention and/or management of type 2 diabetes.

In accordance with the results found about the inhibition of alpha-glucosidase, an increase in the percentage of inhibition of lipase activity from $35.2 \pm 0.2-45.5 \pm 1.2$ was observed in samples pre-treated with Pronase and from $86.2 \pm 0.3-94.3 \pm 1.5$ upon Viscozyme pre-treatment. Obesity is associated with metabolic syndromes and heart disease, thus reducing life quality and expectancy. Pancreatic lipase is responsible for the hydrolysis of triacylglycerols, generating glycerol and fatty acids (Zhang et al., 


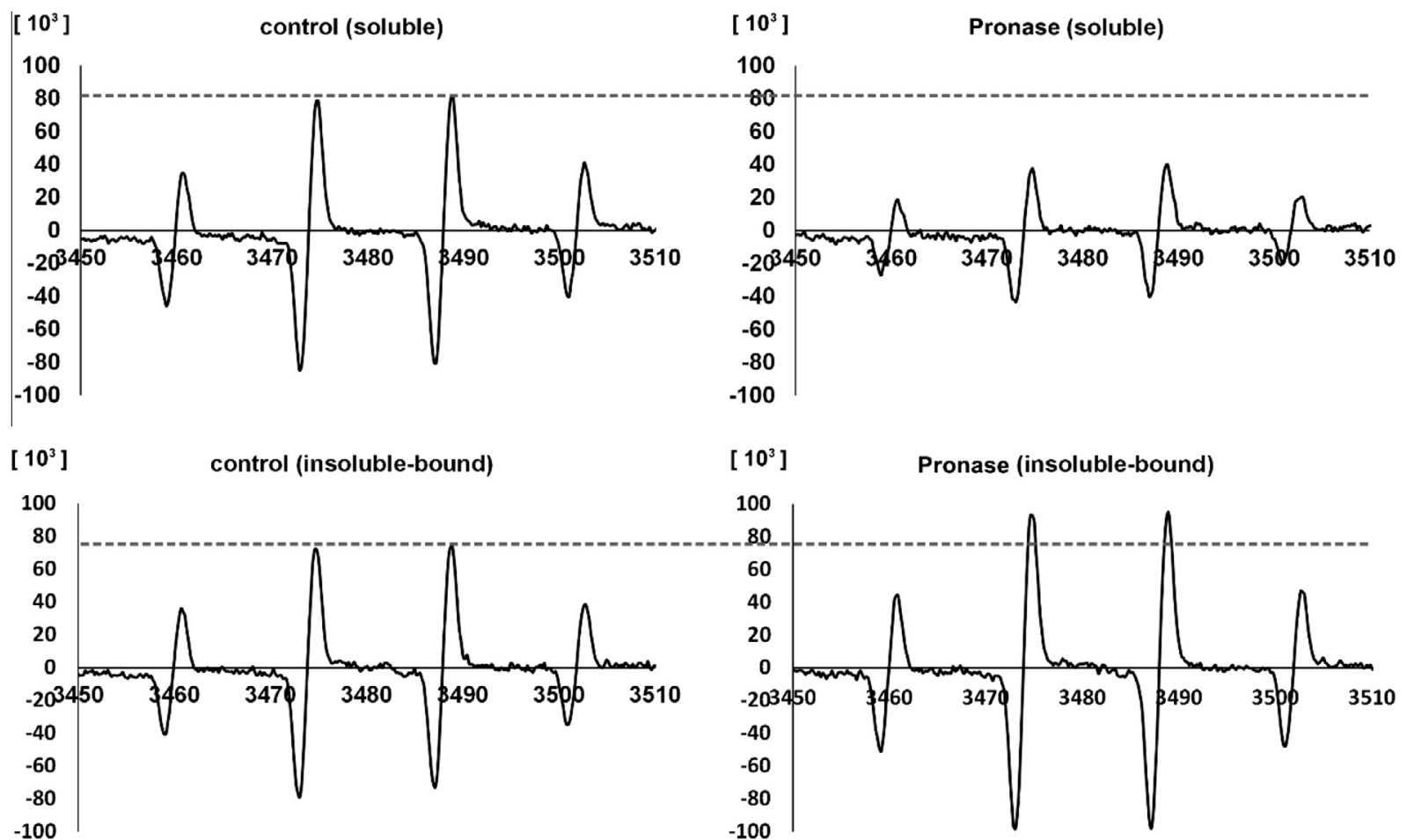

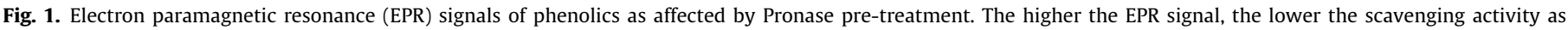
demonstrated by the content of DMPO-OH adducts.
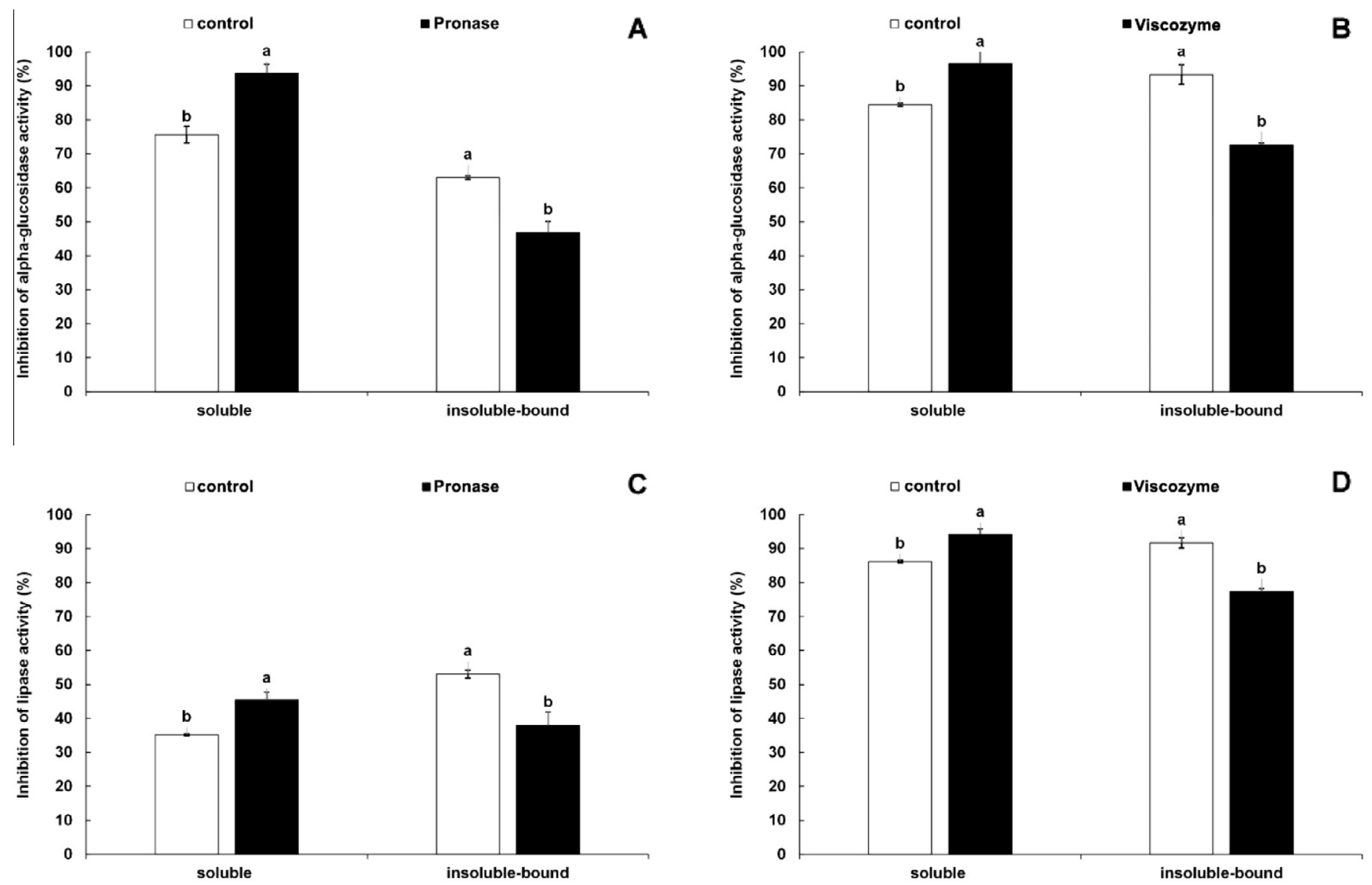

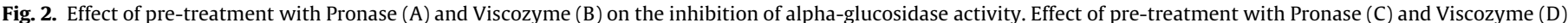

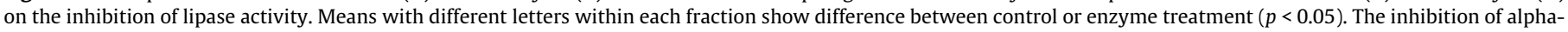
glucosidase and lipase activities was carried out with phenolic extracts at $50 \mathrm{mg} / \mathrm{mL}$ of defatted sample. 
2015). Since lipase activity is related to the absorption of triacylglycerols (Badmaev et al., 2015; Zhang et al., 2015), the increase in the inhibitory activity of the fraction containing soluble phenolics upon Pronase and Viscozyme pre-treatment may be important in the management of body weight and/or prevention of obesity its respective associated diseases.

\subsection{Effect of enzyme treatment on the residue remaining after extraction of soluble phenolics (Experiment II)}

\subsubsection{Total phenolic content}

The effect of enzyme treatment and alkali hydrolysis on the residue remaining after extraction of soluble phenolics is shown in Table 3. Both enzymes were able to release phenolics from their insoluble-bound form, which is helpful in explaining the change in the ratio of soluble to insoluble-bound phenolics as was demonstrated in the first experiment. Viscozyme treatment rendered a higher extraction when compared to Pronase, but lower than those found in the sample hydrolyzed with $\mathrm{NaOH}$. This lends support to the results found in the first experiment that showed an increase in the extraction yield of soluble phenolics but the efficiency was not $100 \%$. In terms of biological application this means that regardless of the treatment (in the starting material or in the residue remaining after extraction of soluble phenolics), some phenolics remain in the insoluble-bound phenolics fraction and will be bioaccessible for microbial action in the colon (Chandrasekara \& Shahidi, 2012).

\subsubsection{Identification and quantification of phenolic compounds}

The data presented thus far demonstrated the ability of Pronase and Viscozyme in improving the extraction of phenolics and potential positive effect in terms of health benefits. Winemaking byproducts serve as good sources of phenolic compounds such as phenolic acids, monomeric flavonoids and proanthocyanidins (de Camargo et al., 2014). In the present study, the major phenolic compounds were tentatively or positively identified and quantified in the samples in the second experiment in order to explain the effects of enzyme treatment on a molecular level (Table 4). $p$ Coumaric, gallic, and caffeic acids, as well as catechin and epicatechin, were positively identified by comparison of their retention times, ion fragmentation patterns with authentic standards, and

\section{Table 3}

Total phenolic content, antioxidant activity, reducing power, and enzyme inhibitory activity of insoluble-bound phenolics of winemaking by-products upon extraction using enzymatic or alkali hydrolysis.

\begin{tabular}{|c|c|c|}
\hline Pronase & Viscozyme & $\mathrm{NaOH}$ \\
\hline \multicolumn{3}{|c|}{ Total phenolic content (mg GAE/g DW) } \\
\hline $13.87 \pm 0.08 \mathrm{Cb}$ & $24.70 \pm 0.14 \mathrm{Ba}$ & $237.7 \pm 4.53 \mathrm{~A}$ \\
\hline \multicolumn{3}{|c|}{ ABTS radical cation scavenging activity ( $\mu \mathrm{mol} T E / g$ DW) } \\
\hline $21.94 \pm 0.30 \mathrm{Bb}$ & $33.75 \pm 0.58 \mathrm{Ba}$ & $655.8 \pm 20.4 \mathrm{~A}$ \\
\hline \multicolumn{3}{|c|}{$D P P H$ radical scavenging activity ( $\mu$ mol TE/g DW) } \\
\hline $25.54 \pm 0.65 \mathrm{Cb}$ & $56.96 \pm 2.72 \mathrm{Ba}$ & $516.9 \pm 10.0 \mathrm{~A}$ \\
\hline \multicolumn{3}{|c|}{ Hydroxyl radical cation scavenging activity ( $\mu \mathrm{mol} C E / g$ DW) } \\
\hline $18.27 \pm 0.20 \mathrm{Bb}$ & $49.05 \pm 1.81 \mathrm{Ba}$ & $337.8 \pm 29.8 \mathrm{~A}$ \\
\hline \multicolumn{3}{|c|}{ Reducing power ( $\mu \mathrm{mol} T E / g$ DW) } \\
\hline $11.96 \pm 0.26 \mathrm{Bb}$ & $17.71 \pm 0.35 \mathrm{Ba}$ & $562.5 \pm 15.4 \mathrm{~A}$ \\
\hline \multicolumn{3}{|c|}{ Inhibition of alpha-glucosidase activity (\%) } \\
\hline $7.35 \pm 3.1 \mathrm{Ba}$ & $7.79 \pm 0.6 \mathrm{Ba}$ & $70.7 \pm 3.6 \mathrm{~A}$ \\
\hline \multicolumn{3}{|c|}{ Inhibition of lipase activity (\%) } \\
\hline $9.71 \pm 0.2 \mathrm{Cb}$ & $24.9 \pm 0.9 \mathrm{Ba}$ & $90.1 \pm 4.2 \mathrm{~A}$ \\
\hline
\end{tabular}

Data represent mean values for each sample \pm standard deviation $(n=3)$. Means followed by different capital letters within a row show difference among enzyme (Pronase or Viscozyme) and alkali treated samples $(p<0.05)$. Means followed by different small letters within a row show difference between Pronase and Viscozyme treated samples $(p<0.05)$. GAE, gallic acid equivalents; CE, catechin equivalents; TE, Trolox equivalents; and DW, dry weight of defatted sample. The inhibition of alpha-glucosidase and lipase activity was carried out with phenolic extracts at $50 \mathrm{mg} / \mathrm{mL}$ of defatted sample. previous studies (Alshikh et al., 2015; Ayoub et al., 2016; de Camargo, Regitano-d'Arce, Gallo, \& Shahidi, 2015; de Camargo et al., 2014). Isorhamnetin was tentatively identified due to its deprotonated molecular ion at $315 \mathrm{~m} / \mathrm{z}$ and $271 \mathrm{~m} / \mathrm{z}$ in $\mathrm{MS}^{2}$ (de Camargo et al., 2014). Procyanidin dimer B, [M - H $]^{-}$at $577 \mathrm{~m} / \mathrm{z}$, gave product ions at 451, 425, and 289 in $\mathrm{MS}^{2}$ (de Camargo et al., 2014) and prodelphinidin dimer B showed $\mathrm{m} / \mathrm{z} 591$ in MS and characteristic ions at $\mathrm{MS}^{2}$, which matched the literature results (Hamed et al., 2014).

p-Coumaric and caffeic acids, as well as procyanidin dimer B were not found in samples upon Pronase treatment and only traces of epicatechin and isorhamnetin were detected. Gallic acid is one of the major phenolic acids found in winemaking by-products (de Camargo et al., 2014). The treatment with Viscozyme rendered twice the concentration of gallic acid when compared to Pronase, whereas the content of catechin was 14 times higher in samples extracted with Viscozyme as compared to Pronase. Furthermore, the efficiency of Viscozyme in extracting prodelphinidin dimer A was $58 \%$ when compared with the chemical extraction $(\mathrm{NaOH})$. As mentioned before, insoluble-bound phenolics are linked to cell wall carbohydrates and proteins. The absence of $p$-coumaric and caffeic acids, as well as procyanidin dimer B, in extracts obtained upon Pronase treatment, and the presence of such compounds in extracts obtained with Viscozyme, suggest that these compounds may be linked to carbohydrates rather than to proteins.

p-Coumaric acid exhibited in vitro and in vivo antiplatelet activity (Luceri et al., 2007). Aflatoxins, which can be found in food products such as peanuts and even milk (de Camargo et al., 2012b; Santili et al., 2015) can cause hepatotoxicity. Caffeic acid phenethyl ester, a caffeic acid derivative, was able to protect AFB1-induced hepatotoxicity in rats (Akçam et al., 2013). Rich sources of proanthocyanidins and simple phenolics have been used to fortify food products and increase the ingestion of dietary phenolics (de Camargo and Vidal et al., 2014; Ma, Kerr, Swanson, Hargrove, \& Pegg, 2014; Zhang, Chen, \& Wang, 2014). Proanthocyanidins are among the major components of insoluble-bound phenolics in winemaking by-products (de Camargo et al., 2014). However, only soluble proanthocyanidins are bioaccessible in the small intestine. Upon microbial action, insoluble-bound proanthocyanidins may be catabolized in the colon, but this depends on the degree of polymerization of such compounds. Furthermore, it has been suggested that the bioavailability of proanthocyanidins decreases with increasing degree of polymerization (de Camargo et al., 2015). The presence of procyanidin B1 has been detected in human serum, which has been attributed to consumption of grape seed extract (Sano et al., 2003). Thus, the presence of $p$ coumaric and caffeic acids, as well as procyanidin dimer B, which were not found in extracts obtained upon Pronase treatment, may have health benefits. Furthermore, the present study demonstrates that not only the identity, but also the quantity of specific phenolics are dependent on the enzyme used. The effect of such differences on the in vitro bioactivity will be discussed in the following sections.

\subsubsection{Antiradical activity and reducing power}

The antioxidant activity and reducing power of extracts obtained upon enzyme or alkali treatment are shown in Table 3. As demonstrated with TPC, the activity was in the order of extracts obtained with $\mathrm{NaOH}>$ Viscozyme $>$ Pronase. Phenolics extracted with Viscozyme showed up to 2.7 higher antioxidant activity, which was found against hydroxyl radicals, as compared with phenolics extracted with Pronase. Hydroxyl radicals are generated in the presence of ferrous ions and hydrogen peroxide. The ability of phenolic compounds in scavenging hydroxyl radicals may be due to chelation of ferrous ion (Wettasinghe \& Shahidi, 2000), but electron donation and eventual neutralization of hydrogen per- 
Table 4

The contents of insoluble-bound phenolics ( $\mu \mathrm{g} / \mathrm{g} \mathrm{DW})$ of winemaking by-products as affected by different extraction procedures.

\begin{tabular}{|c|c|c|c|c|c|c|}
\hline MW & {$[\mathrm{M}-\mathrm{H}]^{-}$} & Other product ions $(\mathrm{m} / \mathrm{z})$ & Identification & Pronase & Viscozyme & $\mathrm{NaOH}$ \\
\hline 164 & 163 & 119 & p-Coumaric acid & nd & $14.68 \pm 0.69 b$ & $83.28 \pm 6.19 a$ \\
\hline 170 & 169 & 125 & Gallic acid & $36.16 \pm 1.78 c$ & $71.68 \pm 4.85 b$ & $180.4 \pm 0.01 \mathrm{a}$ \\
\hline 180 & 179 & 135 & Caffeic acid & nd & $18.49 \pm 1.14 b$ & $308.4 \pm 22.7 a$ \\
\hline 290 & 289 & $245,205,179$ & Catechin & $16.01 \pm 0.31 c$ & $226.3 \pm 27.7 b$ & $494.2 \pm 0.04 a$ \\
\hline 290 & 289 & $245,205,179$ & Epicatechin & $\operatorname{tr}$ & $106.3 \pm 7.15 b$ & $141.9 \pm 13.3 a$ \\
\hline 316 & 315 & 271 & Isorhamnetin & $\operatorname{tr}$ & $241.4 \pm 63.9 b$ & $448.2 \pm 19.7 a$ \\
\hline 578 & 577 & $451,425,289$ & Procyanidin dimer B & nd & $369.6 \pm 26.0 \mathrm{~b}$ & $7282 \pm 580 a$ \\
\hline 592 & 591 & $439,301,289$ & Prodelphinidin dimer A & $142.5 \pm 12.9 c$ & $453.0 \pm 18.8 b$ & $784.8 \pm 29.1 \mathrm{a}$ \\
\hline
\end{tabular}

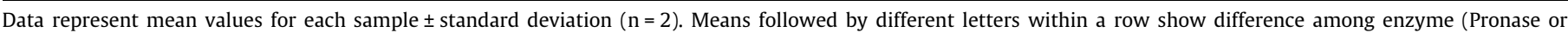
Viscozyme) and alkali treated samples $(p<0.05)$. Abbreviations are: nd, not detected; and tr, trace.

oxide generating water as the final product is also contemplated. In the present study, the ability of phenolic extracts in scavenging hydroxyl radicals was studied, but the capacity of phenolic extracts in scavenging hydrogen peroxide (de Camargo et al., 2014) and their chelating capacity (Ayoub et al., 2016) has already been demonstrated; therefore, phenolic extracts obtained here may also be efficient in scavenging hydrogen peroxide or chelating ferrous ions, thus stopping/preventing the Fenton reaction by reacting with its reagents (hydrogen peroxide and ferrous ions), or products (hydroxyl radicals).

Although extensive studies have been conducted with grapes, their products and by-products (de Camargo et al., 2014; Tao et al., 2016; Weidner, Powałka, Karamać, \& Amarowicz, 2012; Weidner et al., 2013), a direct comparison with the literature is not possible. Extraction conditions such as solvent type and concentration, solid to solvent ratio, $\mathrm{pH}$ and temperature may not only render different yields of phenolic extracts but also different compounds may be extracted under specific conditions (Ayoub et al., 2016; de Camargo and Vieira et al., 2014). Thus, in addition to the already mentioned factors, the present study demonstrated that the enzyme used for phenolic extraction should also be taken into consideration.

\subsubsection{Inhibition of alpha-glucosidase and lipase activities}

The inhibitory activity of phenolics extracts as affected by enzymatic (Pronase or Viscozyme) and alkali extraction is shown in Table 3. Although lower when compared with phenolic extracts obtained with alkali extraction, Pronase and Viscozyme rendered extracts with improved capacity in inhibiting alpha-glucosidase and lipase activities. Phenolics extracted with Pronase inhibited alpha-glucosidase and lipase by $7.35 \pm 3.1$ and $9.71 \pm 0.2 \%$, respectively, whereas the respective inhibition of phenolics extracted with Viscozyme were $7.79 \pm 0.6$ and $24.9 \pm 0.9 \%$. Phenolic compounds are able to form complexes with proteins and this may be due to the formation of hydrogen bonds (de Toledo, Rocha, da Silva, \& Brazaca, 2013), or addition of nucleophiles to oxidized quinones (Kalyanaraman, Premovic, \& Sealy, 1987). The correlation of TPC with antioxidant activity and reducing power of different feedstock has been well documented (Augusto et al., 2014; Ayoub et al., 2016; da Silva, et al., 2016; de Camargo et al., 2014). In the present study, positive correlations existed between TPC and the inhibition of alpha-glucosidase $(\mathrm{r}=0.9389, p<0.001)$ and lipase activity $(\mathrm{r}=0.7300, p=0.017)$, showing that not only the identity but also the concentration of phenolics from different sources should be taken into account.

\section{Conclusion}

The enzyme treatment of the winemaking by-products demonstrated that both Pronase and Viscozyme increased the amount of soluble phenolics while decreasing the content of insoluble-bound phenolics, with a concurrent increase in the ratio of soluble to insoluble-bound phenolics. ABTS radical cation, DPPH radical, and hydroxyl radical scavenging activities, reducing power, and inhibition of alpha-glucosidase and lipase activities were also increased. In addition, treatment of the fraction containing only the insolublebound phenolics, supported the data obtained in the first set of experiments and also demonstrated that specific molecules such as p-coumaric, gallic and caffeic acids, as well as catechin, epicatechin, isorhamnetin, procyanidin dimer $\mathrm{B}$, and prodelphinidin dimer A were better extracted upon treatment with Viscozyme as compared to Pronase. Furthermore, the same trend was observed in the remaining methods used. The present work indicates that enzyme-assisted extraction should be further exploited for the development of functional food ingredients and or nutraceuticals. The antioxidant activity of food phenolics and their potential role in the prevention of several ailments have been well substantiated. Additionally, the positive effects by inhibiting the activity of alphaglucosidase and lipase, which are related to prevention and/or management of diabetes and obesity, respectively, were demonstrated here.

\section{Acknowledgments}

The first author acknowledges FAPESP (São Paulo Research Foundation) for granting an international PhD internship (Process 2015/00336-4). This research is also supported by the doctoral scholarship granted by FAPESP to the first author in Brazil (Process 2012/17683-0). One of us (FS) thanks the Natural Science and Engineering Research Council (NSERC) of Canada for partial financial support.

\section{References}

Akçam, M., Artan, R., Yilmaz, A., Ozdem, S., Gelen, T., \& Nazıroğlu, M. (2013). Caffeic acid phenethyl ester modulates aflatoxin B1-induced hepatotoxicity in rats. Cell Biochemistry and Function, 31, 692-697.

Alasalvar, C., \& Bolling, B. W. (2015). Review of nut phytochemicals, fat-soluble bioactives, antioxidant components and health effects. British Journal of Nutrition, 113, S68-S78.

Alshikh, N., de Camargo, A. C., \& Shahidi, F. (2015). Phenolics of selected lentil cultivars: Antioxidant activities and inhibition of low-density lipoprotein and DNA damage. Journal of Functional Foods, 18 (Part B), 1022-1038.

Ambigaipalan, P., Al-Khalifa, A. S., \& Shahidi, F. (2015). Antioxidant and angiotensin I converting enzyme (ACE) inhibitory activities of date seed protein hydrolysates prepared using Alcalase, Flavourzyme and Thermolysin. Journal of Functional Foods, 18 (Part B), 1125-1137.

Augusto, T. R., Salinas, E. S. S., Alencar, S. M., d'Arce, M. A. B. R., de Camargo, A. C., \& Vieira, T. M. F. S. (2014). Phenolic compounds and antioxidant activity of hydroalcoholic extracts of wild and cultivated murtilla (Ugni molinae Turcz.). Food Science and Technology (Campinas), 34, 667-679.

Ayoub, M., de Camargo, A. C., \& Shahidi, F. (2016). Antioxidants and bioactivities of free, esterified and insoluble-bound phenolics from berry seed meals. Food Chemistry, 197 (Part A), 221-232.

Badmaev, V., Hatakeyama, Y., Yamazaki, N., Noro, A., Mohamed, F., Ho, C.-T., \& Pan, M.-H. (2015). Preclinical and clinical effects of Coleus forskohlii, Salacia reticulata and Sesamum indicum modifying pancreatic lipase inhibition in vitro and reducing total body fat. Journal of Functional Foods, 15, 44-51. 
Chandrasekara, A., \& Shahidi, F. (2012). Bioaccessibility and antioxidant potential of millet grain phenolics as affected by simulated in vitro digestion and microbial fermentation. Journal of Functional Foods, 4, 226-237.

Cheng, V. J., Bekhit, A. E. A., McConnell, M., Mros, S., \& Zhao, J. (2012). Effect of extraction solvent, waste fraction and grape variety on the antimicrobial and antioxidant activities of extracts from wine residue from cool climate. Food Chemistry, 134, 474-482.

da Silva, P. P. M., Casemiro, R. C., Zillo, R. R., de Camargo, A. C., Prospero, E. T. P., \& Spoto, M. H. F. (2014). Sensory descriptive quantitative analysis of unpasteurized and pasteurized juçara pulp (Euterpe edulis) during long-term storage. Food Science \& Nutrition, 2, 321-331.

da Silva, J. K., Cazarin, C. B. B., Correa, L. C., Batista, Â. G., Furlan, C. P. B., Biasoto, A. C. T., ... Pereira, G. E. (2016). Bioactive compounds of juices from two Brazilian grape cultivars. Journal of the Science of Food and Agriculture, 96, 1990-1996.

de Camargo, A. C., Regitano-d'Arce, M. A. B., Biasoto, A. C. T., \& Shahidi, F. (2014). Low molecular weight phenolics of grape juice and winemaking byproducts: Antioxidant activities and inhibition of oxidation of human low-density lipoprotein cholesterol and DNA strand breakage. Journal of Agricultural and Food Chemistry, 62, 12159-12171.

de Camargo, A. C., Regitano-d'Arce, M. A. B., Gallo, C. R., \& Shahidi, F. (2015). Gamma-irradiation induced changes in microbiological status, phenolic profile and antioxidant activity of peanut skin. Journal of Functional Foods, 12, 129-143.

de Camargo, A. C., Vidal, C. M. M., Canniatti-Brazaca, S. G., \& Shahidi, F. (2014). Fortification of cookies with peanut skin: Effects on the composition, polyphenols, antioxidant properties and sensory quality. Journal of Agricultural and Food Chemistry, 62, 11228-11235.

de Camargo, A. C., Vieira, T. M. F. S., Rasera, G. B., Canniatti-Brazaca, S. G., de Alencar, S. M., \& Regitano-d'Arce, M. A. B. (2014). Lower solvent concentration and time for extraction of peanut skin antioxidants at optimized conditions. In R. W. Cook (Ed.), Peanuts: Production, nutritional content and health implications (pp. 31-50). New York: Nova Publishers.

de Camargo, A. C., Vieira, T. M. F. S., Regitano-D’Arce, M. A. B., de Alencar, S. M., Calori-Domingues, M. A., \& Canniatti-Brazaca, S. G. (2012a). Gamma radiation induced oxidation and tocopherols decrease in in-shell, peeled and blanched peanuts. International Journal of Molecular Sciences, 13, 2827-2845.

de Camargo, A. C., Vieira, T. M. F. S., Regitano-d'Arce, M. A. B., de Alencar, S. M., Calori-Domingues, M. A., Spoto, M. H. F., \& Canniatti-Brazaca, S. G. (2012b). Gamma irradiation of in-shell and blanched peanuts protects against mycotoxic fungi and retains their nutraceutical components during long-term storage. International Journal of Molecular Sciences, 13, 10935-10958.

de Toledo, N. M. V., Rocha, L. C., da Silva, A. G., \& Brazaca, S. G. C. (2013). Interaction and digestibility of phaseolin/polyphenol in the common bean. Food Chemistry, $138,776-780$

Eom, S.-H., Lee, S.-H., Yoon, N.-Y., Jung, W.-K., Jeon, Y.-J., Kim, S.-K., ... Lee, M.-S. (2012). A-Glucosidase- and $\alpha$-amylase-inhibitory activities of phlorotannins from Eisenia bicyclis. Journal of the Science of Food and Agriculture, 92, 2084-2090.

Hamed, A. I., Al-Ayed, A. S., Moldoch, J., Piacente, S., Oleszek, W., \& Stochmal, A. (2014). Profiles analysis of proanthocyanidins in the argun nut (Medemia argun - an ancient Egyptian palm) by LC-ESI-MS/MS. Journal of Mass Spectrometry, 49, 306-315.

Kalyanaraman, B., Premovic, P. I., \& Sealy, R. C. (1987). Semiquinone anion radicals from addition of amino acids, peptides, and proteins to quinones derived from oxidation of catechols and catecholamines. An ESR spin stabilization study. Journal of Biological Chemistry, 262, 11080-11087.

Luceri, C., Giannini, L., Lodovici, M., Antonucci, E., Abbate, R., Masini, E., \& Dolara, P. (2007). p-Coumaric acid, a common dietary phenol, inhibits platelet activity in vitro and in vivo. British Journal of Nutrition, 97, 458-463.

Ma, Y. Y., Kerr, W. L., Swanson, R. B., Hargrove, J. L., \& Pegg, R. B. (2014). Peanut skins-fortified peanut butters: Effect of processing on the phenolics content, fibre content and antioxidant activity. Food Chemistry, 145, 883-891.
Marrelli, M., Menichini, F., Statti, G. A., Bonesi, M., Duez, P., Menichini, F., \& Conforti, F. (2012). Changes in the phenolic and lipophilic composition, in the enzyme inhibition and antiproliferative activity of Ficus carica L. cultivar Dottato fruits during maturation. Food and Chemical Toxicology, 50, 726-733.

Montella, R. Coïsson, J. D. Travaglia, F. Locatelli, M., Malfa, P., Martelli, A. \& Arlorio, M. (2013). Bioactive compounds from hazelnut skin (Corylus avellana L.): Effects on Lactobacillus plantarum P17630 and Lactobacillus crispatus P17631. Journal of Functional Foods, 5, 306-315.

Oyaizu, M. (1986). Studies on products of browning reaction - Antioxidative activities of products of browning reaction prepared from glucosamine. The Japanese Journal of Nutrition and Dietetics, 44, 307-315.

Papillo, V. A., Vitaglione, P., Graziani, G., Gokmen, V., \& Fogliano, V. (2014). Release of antioxidant capacity from five plant foods during a multistep enzymatic digestion protocol. Journal of Agricultural and Food Chemistry, 62, 4119-4126.

Re, R., Pellegrini, N., Proteggente, A., Pannala, A., Yang, M., \& Rice-Evans, C. (1999). Antioxidant activity applying an improved ABTS radical cation decolorization assay. Free Radical Biology \& Medicine, 26, 1231-1237.

Sano, A., Yamakoshi, J., Tokutake, S., Tobe, K., Kubota, Y., \& Kikuchi, M. (2003). Procyanidin B1 is detected in human serum after intake of proanthocyanidinrich grape seed extract. Bioscience, Biotechnology, and Biochemistry, 67, $1140-1143$.

Santili, A. B. N., DeCamargo, A. C., Nunes, R. D. S. R., Gloria, E. M. D., Machado, P. F. Cassoli, L. D., Dias, C. T. D. S., \& Calori-Domingues, M. A. (2015). Aflatoxin M1 in raw milk from different regions of São Paulo state - Brazil. Food Additives E Contaminants: Part B, 8, 1-8.

Shahidi, F. \& Ambigaipalan, P. (2015). Phenolics and polyphenolics in foods, beverages and spices: Antioxidant activity and health effects - A review. Journal of Functional Foods, 18 (Part B), 820-897.

Swain, T., \& Hillis, W. E. (1959). The phenolic constituents of Prunus domestica. I.The quantitative analysis of phenolic constituents. Journal of the Science of Food and Agriculture, 10, 63-68.

Tao, Y., Sun, D. W., Górecki, A., Błaszczak, W., Lamparski, G., Amarowicz, R., ... Fornal, J. (2016). A preliminary study about the influence of high hydrostatic pressure processing in parallel with oak chip maceration on the physicochemical and sensory properties of a young red wine. Food Chemistry, 194, 545-554.

Vicente, S. J. V., Ishimoto, E. Y., \& Torres, E. A. F. S. (2014). Coffee modulates transcription factor Nrf2 and highly increases the activity of antioxidant enzymes in rats. Journal of Agricultural and Food Chemistry, 62, 116-122.

Weidner, S., Powałka, A., Karamać, M., \& Amarowicz, R. (2012). Extracts of phenolic compounds from seeds of three wild grapevines-comparison of their antioxidant activities and the content of phenolic compounds. International Journal of Molecular Sciences, 13, 3444-3457.

Weidner, S., Rybarczyk, A., Karamać, M., Król, A., Mostek, A., Grębosz, J., \& Amarowicz, R. (2013). Differences in the phenolic composition and antioxidant properties between Vitis coignetiae and Vitis vinifera seeds extracts. Molecules, 18, 3410-3426.

Wettasinghe, M., \& Shahidi, F. (2000). Scavenging of reactive-oxygen species and DPPH free radicals by extracts of borage and evening primrose meals. Food Chemistry, 70, 17-26.

Yeo, J., \& Shahidi, F. (2015). Critical evaluation of changes in the ratio of insoluble bound to soluble phenolics on antioxidant activity of lentils during germination. Journal of Agricultural and Food Chemistry, 63, 379-381.

Zhang, X., Chen, F., \& Wang, M. (2014). Antioxidant and antiglycation activity of selected dietary polyphenols in a cookie model. Journal of Agricultural and Food Chemistry, 62, 1643-1648.

Zhang, B., Deng, Z., Ramdath, D. D., Tang, Y., Chen, P. X., Liu, R., ... Liu, Q. (2015) Phenolic profiles of 20 Canadian lentil cultivars and their contribution to antioxidant activity and inhibitory effects on $\alpha$-glucosidase and pancreatic lipase. Food Chemistry, 172, 862-872. 